\title{
A detailed crust to upper mantle structure: Comparison between Algerian and Alboran domains in the Western Mediterranean
}

\author{
Ajay Kumar Ajay Kumar (1,2), Manel Fernàndez (1), Jaume Vergés (1), Montserrat Torne (1), and Ivone \\ Jimenez-Munt (1) \\ (1) Group of Dynamics of the Lithosphere, Institute of Earth Sciences Jaume Almera, ICTJA-CSIC, Spain \\ (akumar@ictja.csic.es), (2) Department of Geodynamics and Geophysics, Universitat de Barcelona, Barcelona, Spain
}

We present a comparison of the present-day crust to upper-mantle (400km) structure in the Western Mediterranean along two NW-SE oriented transects in the Alboran and Algerian domains. The Alboran domain transect crosses the Betics, the Alboran Basin, and the northern margin of Africa between the Tell and Rif mountains. The Algerian domain transect crosses Valencia Trough, the Balearic Promontory, the Algerian basin and ends in the Tell-Atlas Mountains in the northern margin of Africa. We model the thermal, compositional, density and seismic velocity structure, also incorporating slabs imaged by seismic tomography using recently updated version of the LitMod2D, an integrated geophysical-petrological modelling tool. LitMod2D combines data from petrology, geochemistry and geophysics in a self-consistent thermodynamic framework. The resulting structure is constrained by simultaneously fitting elevation, gravity, geoid and surface heat flow to reduce the uncertainties in the modelling. Further, we calculate synthetic receiver functions and surface wave dispersion curves from our velocity model. We do this to circumvent non-uniqueness of seismic tomography models and directly compare the prediction from our velocity model with the observed seismological data. Preliminary results suggest that crust is thickest beneath the Betics and thins beneath the Alboran basin within a distance of $\sim 100 \mathrm{~km}$. Farther SE, crust gradually thickens beneath the north margin of Africa, between Tell and Rif mountains over $~ 300$ $\mathrm{km}$ distance. The LAB shows a similar trend though affected by the presence of the slab underneath Betics. For the Algerian domain transect, maximum crustal thickness occurs beneath the Tell-Atlas Mountains with noticeable variations across the Algerian basin, Balearic Promontory and Valencia Trough, the LAB showing a similar tendency. Comparing the modelled geometries suggests that both transects have opposite trends with the deepest Moho and LAB in the NW side of the Alboran domain transect and in the SE side of the Algerian domain transect, imposing important constrains on the geodynamic evolution of the Western Mediterranean.

This is a SUBITOP (674899-SUBITOP-H2020-MSCA-ITN-2015) and MITE (CGL2014-59516) contribution. 